\title{
Perceived benefits and barriers to physical activity in a nationally representative sample in the European Union
}

\author{
Hans-Joachim Franz Zunft ${ }^{1}$, Dietlinde Friebe ${ }^{1}$, Brigitte Seppelt ${ }^{1}$, Kurt Widhalm², \\ Anne-Marie Remaut de Winter ${ }^{3}$, Maria Daniel Vaz de Almeida ${ }^{4}$, \\ John M Kearney ${ }^{5}$ and Michael Gibney ${ }^{5}$ \\ 'German Institute of Human Nutrition, Arthur-Scheunert-Allee 1 14-1 16, D-1 4558 Bergholz-Rehbruecke, Germany: \\ ${ }^{2}$ University Kinderklinik, Wahringer Guertel 18-20, A-1090 Vienna, Austria: ${ }^{3}$ University of Ghent, Faculty of \\ Agricultural and Applied Biological Science, CISNA/ICFSN, Coupure Links 653, B-9000 Ghent, Belgium: \\ ${ }^{4}$ Curso de Ciencias da Nutricao, R Dr Roberto Frias, 4000-Porto, Portugal: ${ }^{5}$ Institute of European Food Studies, \\ Trinity College, Dublin, Ireland
}

\begin{abstract}
Objective: To examine the attitudes of consumers, in particular their perceived benefits and barriers to physical activity from all EU member states, and having a measure of prevailing levels of activity, inactivity and self-reported body weight and body shape.

Design: Cross-sectional survey using an interview-assisted face-to-face questionnaire. Setting: The survey was conducted between March and April 1997 in the 15 member states of the EU.

Subjects: Overall, 15239 EU subjects, classified according to sex, age (six levels) and highest level of education attained (primary, secondary or tertiary), completed the survey. Sample selection of subjects in each EU member state was quota-controlled to ensure they were nationally representative.

Results: The most important motivation for people to participate in physical activity is to maintain good health (42\%), to release tension $(30 \%)$ and to get fit $(30 \%)$. The importance of the health argument is highest in older persons and in subjects with a primary education level. Only $13 \%$ of the EU population (16\% of women, $10 \%$ of men) perceived losing weight as a benefit of physical exercise. The most important barriers to increase physical activity are work or study commitments (28\%) and the subjects' belief that they are not 'the sporty type' (25\%). There is considerable between-country variation in the answering pattern within the EU.
\end{abstract}

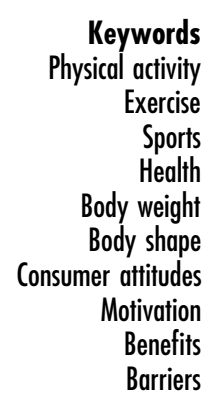

Obesity is a serious and chronic medical condition associated with a wide range of life-threatening diseases and resulting in enormous financial costs being born by health-care systems and the community itself. The prevalence of obesity in the affluent societies has also been increasing during recent years ${ }^{1,2}$. Therefore, public health programmes focused on a long-term control of body weight are highly relevant. Their main target has to be a concomitant change in dietary habits and in the level of physical exercise ${ }^{3-10}$. A positive health effect of increased physical activity has been shown for other outcomes ${ }^{11-13}$.

Many epidemiological studies have demonstrated a close relationship between physical activity and morbidity and mortality from cardiovascular diseases $^{14-16}$. Regular physical exercise clearly promotes health and well-being and is important in the prevention of cardiovascular diseases. Positive effects are especially observed on the retardation of atherosclerotic processes and the reduction of high blood pressure ${ }^{17}$. Moreover, the risk of other diseases is also influenced in a favourable way. Increased physical activity improves bone structure and contributes to the prevention of osteoporosis and may help to control body weight and normalize insulin sensitivity and glucose tolerance ${ }^{18-22}$.

Until now, the long-term success of strategies to change lifestyle and to increase the physical activity level has been insufficient. The reasons for the failure in these programmes are not so well-known. Therefore, in order to develop more successful public health strategies, it is necessary to investigate the reasons driving people to a certain nutritional and/or physical behaviour, to recognize the attitudes of individuals towards the recommendations of health promotion programmes and to determine the interrelationship between benefits and barriers motivating or demotivating people to participate in such programmes. To 
answer these questions a study was performed in the 15 EU countries.

\section{Methods}

The study design and methods of sampling have been described in detail elsewhere ${ }^{23}$. In brief, a questionnaire including 12 close-ended questions on attitudes to physical activity, body weight and health was developed by a scientific group headed by the Institute of European Food Studies (IEFS), Dublin, Ireland. Approximately 1000 adults, aged 15 and upwards, from each EU member state were selected to complete the interview-assisted face-to-face questionnaire. Overall, 15239 subjects in the EU completed the questionnaire. The interviews were carried out as a part of 'Eurobus'. In each member state, subject selection was quotacontrolled to make the sample nationally representative.

Subjects were classified according to sex, age (six levels) and highest level of education achieved (primary, secondary or tertiary). Results were calculated, on the one hand, for the combined EU sample weighted for population size to ensure that those member states with a small population size were not given undue emphasis in the context of the total EU and, on the other hand, for national profiles in terms of gender, age and regional distribution.
In order to detect relationships between the high number of categorical data delivered by the questionnaires they were analysed by the chi-squared automatic interaction detection algorithm (CHAID) using the program Answer Tree (SPSS Inc.). The data were distributed in disjunct subgroups being defined by predictors for nominal and ordinal dependent variables. The hierarchical order of the subgroups delivered by the program is an estimate of the priority of the independent variables. For each subgroup a response index was calculated representing the ratio of the number of persons having the considered characteristics of the dependent variable in this subgroup related to the entire sample. The results calculated by CHAID analysis are given as an example in Figure 1. In the other cases they are cited in the text.

\section{Results}

\section{Perceived benefits}

The first question aims to identify what motivates people to participate in physical activity across the EU. The most important perceived reasons or benefits for taking part in physical activity are summarized in Table 1. The top three reasons for participation in physical exercise were 'to maintain good health',

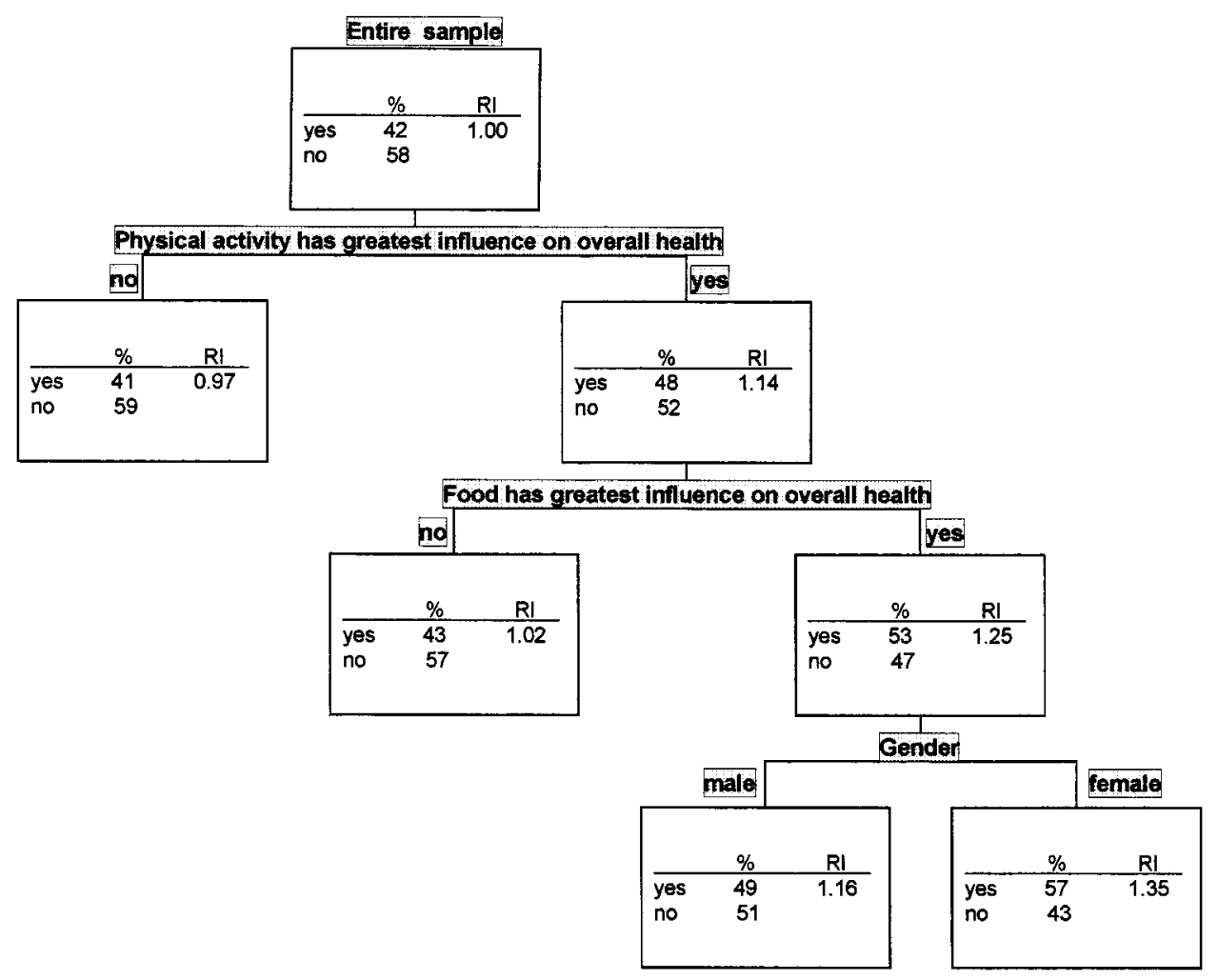

Fig. 1 Percentage of subjects mentioning or not mentioning 'to maintain good health' as a benefit of taking part in physical activity (results of CHAID analysis). RI; response index, i.e. ratio of the percentage of positive answers in a subgroup divided by the percentage of positive answers in the entire sample 
Table 1 Percentage of subjects in each member state selecting different perceived motivating factors for participation in physical activity

\begin{tabular}{|c|c|c|c|c|c|c|c|c|}
\hline Country & $\begin{array}{l}\text { To maintain } \\
\text { good health }\end{array}$ & $\begin{array}{l}\text { To release } \\
\text { tension }\end{array}$ & To get fit & $\begin{array}{l}\text { To be out } \\
\text { of doors }\end{array}$ & To socialize & $\begin{array}{l}\text { To control } \\
\text { weight }\end{array}$ & For fun & $\begin{array}{c}\text { Do not } \\
\text { participate }\end{array}$ \\
\hline Austria & 44 & 22 & 21 & 38 & 22 & 9 & 13 & 4 \\
\hline Belgium & 45 & 26 & 33 & 14 & 14 & 12 & 10 & 16 \\
\hline Denmark & 44 & 25 & 22 & 22 & 35 & 9 & 18 & 6 \\
\hline Finland & 41 & 33 & 32 & 37 & 9 & 14 & 5 & $<1$ \\
\hline France & 28 & 33 & 29 & 16 & 12 & 7 & 10 & 18 \\
\hline Germany & 49 & 24 & 34 & 25 & 13 & 11 & 7 & 7 \\
\hline Greece & 49 & 23 & 24 & 9 & 6 & 25 & 8 & 17 \\
\hline Ireland & 38 & 27 & 27 & 32 & 17 & 19 & 14 & 5 \\
\hline Italy & 47 & 41 & 27 & 18 & 12 & 15 & 7 & 9 \\
\hline Luxembourg & 39 & 27 & 29 & 9 & 16 & 10 & 16 & 14 \\
\hline Netherlands & 34 & 39 & 26 & 9 & 22 & 13 & 19 & 9 \\
\hline Portugal & 21 & 18 & 8 & 15 & 12 & 7 & 8 & 49 \\
\hline Spain & 55 & 38 & 32 & 17 & 13 & 16 & 9 & 4 \\
\hline Sweden & 44 & 16 & 36 & 27 & 15 & 17 & 11 & 5 \\
\hline UK & 37 & 22 & 34 & 19 & 16 & 15 & 12 & 8 \\
\hline EU average* & 42 & 30 & 30 & 20 & 14 & 13 & 10 & 11 \\
\hline
\end{tabular}

* Weighted according to population size.

'to release tension' and 'to get fit'. There was a wide interstate variation in the selections. 'To maintain good health' varied from $21 \%$ in Portugal to $55 \%$ in Spain. Forty-one per cent of Italian subjects cited 'to release tension' as an important reason for participation in physical activity, compared to $16 \%$ of Swedish subjects. Otherwise, Swedish subjects were more concerned about getting fit (36\%) while only $8 \%$ of the Portuguese saw 'to get fit' as an important motivation factor for participation in physical activity. The proportions of EU respondents believing 'to socialize', 'to control weight' and 'to have fun' were good reasons for participating in physical activity were 14\%, 13\% and $10 \%$, respectively. The variable 'do not participate in any form of physical activity/exercise' showed the greatest intercountry variation in values ranging from $<1 \%$ in Finland to almost half of the Portuguese population.

When the motivating factors for participation in physical exercise were examined by the various demographics, 'for good health' was regarded as being the most important variable across all demographics, especially among those aged 55+ years and those with a primary-level education (Table 2).
The factors 'achievement', 'competition', 'concentration' and other and uncertain answers were cited by less than 5\% of the subjects and, therefore, are not given in the table.

The individuals mentioning 'to maintain good health' as a reason for physical exercise were analysed by CHAID (Figure 1). The highest response index of 1.35 is found among women recognizing both diet and physical activity as important factors for health. This index means that within this subgroup the portion of individuals believing in a positive health effect of these influencing factors is higher by approximately one-third than in the entire sample questioned. Male individuals with an identical answering pattern show a smaller response index of only 1.16. There is, however, no relationship between these answering profiles to the real physical activity level recorded by the same individuals.

Younger subjects educated to tertiary level were more inclined to choose 'to get fit' (Table 2). While 20\% of EU respondents claim that 'to be out of doors' was a motivating factor for taking part in physical activity/ exercise, this level rose to $25 \%$ for those with primarylevel education and to $30 \%$ for subjects aged $55+$ years.

Table 2 Percentage of EU subjects selecting different perceived motivating factors for participating in physical activity classified by demographics (age, sex and education level)

\begin{tabular}{|c|c|c|c|c|c|c|c|c|}
\hline \multirow[b]{2}{*}{ Motivating factors } & \multicolumn{3}{|c|}{ Age (years) } & \multicolumn{2}{|c|}{ Sex } & \multicolumn{3}{|c|}{ Education level } \\
\hline & $15-34$ & $35-54$ & $55+$ & Male & Female & Primary & Secondary & Tertiary \\
\hline To release tension & 32 & 34 & 21 & 29 & 30 & 23 & 31 & 35 \\
\hline To be out of doors & 13 & 19 & 30 & 21 & 19 & 25 & 18 & 16 \\
\hline To maintain good health & 39 & 42 & 47 & 41 & 43 & 46 & 40 & 42 \\
\hline To socialize & 15 & 12 & 15 & 14 & 14 & 15 & 14 & 11 \\
\hline To control weight & 15 & 12 & 11 & 10 & 16 & 12 & 14 & 12 \\
\hline For fun & 14 & 9 & 4 & 12 & 8 & 6 & 11 & 13 \\
\hline To get fit & 36 & 30 & 23 & 30 & 30 & 26 & 30 & 38 \\
\hline Do not participate & 8 & 11 & 13 & 9 & 12 & 14 & 10 & 7 \\
\hline
\end{tabular}


Table 3 Percentage of subjects in each member state selecting 'to release tension' classified by education level and gender

\begin{tabular}{|c|c|c|c|c|c|c|}
\hline \multirow[b]{2}{*}{ Country } & \multicolumn{3}{|c|}{ Male } & \multicolumn{3}{|c|}{ Female } \\
\hline & Primary & Secondary & Tertiary & Primary & Secondary & Tertiary \\
\hline Austria & 22 & 24 & 32 & 13 & 21 & 26 \\
\hline Belgium & 5 & 21 & 43 & 18 & 24 & 40 \\
\hline Denmark & 26 & 35 & 53 & 18 & 23 & 33 \\
\hline Finland & 29 & 31 & 37 & 32 & 35 & 49 \\
\hline France & 30 & 34 & 31 & 20 & 32 & 40 \\
\hline Germany & 19 & 36 & 34 & 18 & 23 & 28 \\
\hline Greece & 15 & 22 & 32 & 13 & 28 & 34 \\
\hline Ireland & 19 & 27 & 27 & 20 & 29 & 42 \\
\hline Italy & 25 & 39 & 41 & 35 & 45 & 52 \\
\hline Luxembourg & 9 & 26 & 40 & 22 & 33 & 44 \\
\hline Netherlands & 25 & 38 & 49 & 20 & 38 & 50 \\
\hline Portugal & 13 & 27 & 29 & 9 & 28 & 38 \\
\hline Spain & 30 & 38 & 43 & 39 & 50 & 49 \\
\hline Sweden & 8 & 12 & 20 & 14 & 17 & 30 \\
\hline UK & 7 & 21 & 31 & 14 & 21 & 30 \\
\hline EU average* & 22 & 31 & 34 & 24 & 31 & 37 \\
\hline
\end{tabular}

*Weighted according to population size.

'To control weight' was not perceived to be important in motivating subjects to participate in physical activity. Only $13 \%$ of the European population cited this variable, among these more females (16\%) than males $(10 \%)$. The 'to release tension' variable was regarded as more important for younger and middleaged subjects and those with a secondary and tertiarylevel education. This higher choice of 'to release tension' among these groups may be a reflection of their work routine or lifestyle. The percentage of subjects in each member state selecting 'to release tension' classified by gender is shown in Table 3. In almost all member states there was a clear educationrelated increase for both males and females. Compared to subjects educated to primary or secondary level, subjects with a tertiary-level education were more likely to choose this item as a perceived benefit to participate in physical exercise.

A CHAID analysis revealed that the benefit 'to control weight' was most frequently mentioned (32\%) by women perceiving themselves to be overweight and being physically active for $1.5-4.5$ hours per week. Only $21 \%$ of men with the same characteristics gave this answer. Twenty-three per cent of women and 18\% of men wish to reduce their body weight by their effort in physical exercise. Surprisingly, these data do not correlate with the real body mass index (BMI) of the subjects. Among women this motivation slightly increases parallel to the recorded physical exercise, women being active up to 1 hour, $1.5-4.5$ hours and more than 5 hours per week mention the factor 'to control weight' with a frequency of $13 \%, 19 \%$ and $16 \%$, respectively. This tendency was not observed among male subjects. There is also a positive relationship between the factor 'to control weight' and the selfestimated BMI of the subjects. Thirty-one per cent of overweight and $26 \%$ of obese women expect to normalize their perceived body weight by being active. Among obese men recording to be active more than 5 hours per week there is also a relatively high percentage (21\%) of subjects who expect a normalizing effect on their body weight.

There was an age-related increase in those people selecting the response 'I do not participate in any activity', while the opposite trend occurred with increasing education level with $14 \%$ primary-educated subjects versus only $7 \%$ of those with a tertiary-level education selecting this variable. This relationship between education level and the selection of 'I do not participate' was examined further across the 15 member states (Table 4). While an education-related decrease occurred in all but one member state (Finland, where less than $1 \%$ of respondents with a primary, secondary or tertiary-level education did not engage

Table 4 Percentage of subjects in each member state who selected 'I do not participate in any physical activity/exercise' classified by education level

\begin{tabular}{lccc}
\hline Country & Primary & Secondary & Tertiary \\
\hline Austria & 6 & 3 & 2 \\
Belgium & 26 & 17 & 9 \\
Denmark & 7 & 4 & 5 \\
Finland & 1 & 1 & 1 \\
France & 27 & 18 & 14 \\
Germany & 10 & 5 & 3 \\
Greece & 30 & 12 & 10 \\
Ireland & 11 & 4 & 1 \\
Italy & 12 & 9 & 4 \\
Luxembourg & 23 & 9 & 6 \\
Netherlands & 10 & 10 & 7 \\
Portugal & 61 & 29 & 23 \\
Spain & 5 & 2 & 4 \\
Sweden & 6 & 6 & 2 \\
UK & 13 & 9 & 3 \\
EU average* & 14 & 10 & 7 \\
\hline
\end{tabular}

\footnotetext{
${ }^{*}$ Weighted according to population size.
} 
in some form of exercise) there was considerable variation in the strength of decrease from a gradual decrease in Denmark, the Netherlands and Spain to a large reduction in Belgium, Greece, Luxembourg and Portugal. Indeed, Portugal was unique among the 15 member states in that the percentages in all education levels exceeded the other countries by a factor of two to three. As many as $61 \%$ of Portuguese subjects with primary-level education did not participate in any form of physical activity and this value dropped to just $23 \%$ among those educated to tertiary level.

Conflicting statements can be observed analysing those subjects not perceiving a benefit from physical exercise and simultaneously citing to be inactive. Indeed, only $10 \%$ of these individuals ( $12 \%$ of female, $9 \%$ of male) recorded no physical activity. However, $24 \%$ of men and $23 \%$ of women believing themselves to be inactive, were in fact participating in some physical activity for up to 1 hour per week.

\section{Perceived barriers}

The second question aims to assess the perceived barriers which people may have to participating in physical activity. On observation of the EU average, 'work/study commitments' was the most frequently perceived barrier cited for not increasing participation in physical activity at $28 \%$, followed by 'not the sporty type' at 25\% (Table 5). The remaining perceived barriers to increase one's physical activity were not regarded as being as important. Indeed the percentage of EU subjects selecting 'looking after children/elderly relatives' and 'no need to do any more' is $12 \%$. There were, however, significant variations between countries, particularly for the barrier 'work/study commitments' with $46 \%$ of the Italian respondents selecting this barrier in comparison to only $13 \%$ of the German respondents. Thirty-three per cent of German subjects believed that 'not the sporty type' was a barrier in comparison to $12 \%$ of Finnish subjects. Over a quarter of Spanish subjects felt 'poor health' was a barrier to partaking in physical exercise and one-fifth of this population also believed they were too old, compared with the EU average of one in 10 subjects.

Just as there was considerable interstate variation in the perceived barriers to increasing participation level in physical exercise, there were also marked differences in percentages across demographics (Table 6). Respondents who were younger, educated to tertiary level and who were male, were more inclined to choose 'work/study commitments' as a major barrier to increasing levels of physical activity especially compared to primary-educated subjects (16\%). 'Looking after children/elderly relatives' was an important barrier for females with more than three times as many (18\%) selecting this barrier compared to males (5\%). The barriers 'lack of facilities', 'no-one to do it with', 'fear of injury', 'shy/embarrassment', 'waste of time' were cited by less than $10 \%$ each.

The relationship between education level and the barrier 'not the sporty type' was further examined across the 15 EU member states (Table 7). The educationrelated decrease seen in the average EU sample was apparent in 10 of the member states. In the other five countries there was little effect of education level on the selection of this barrier. As education level of subjects increased from primary to tertiary level, so did the percentage of subjects mentioning the barrier 'work/study commitments' in all 15 member states (Table 7). Thus, for tertiary-educated subjects in all 15 member states, this time-related barrier represents an important obstacle to increasing their level of physical activity. In this instance the differences across education level within member states tended to be greater

Table 5 Percentage of subjects in each member state selecting different perceived barriers to increasing levels of physical activity/exercise

\begin{tabular}{|c|c|c|c|c|c|c|c|c|}
\hline Country & Work/study & $\begin{array}{c}\text { Not the } \\
\text { sporty type }\end{array}$ & $\begin{array}{l}\text { Looking after } \\
\text { children/elderly }\end{array}$ & No need & Poor health & No energy & Too old & Other \\
\hline Austria & 32 & 22 & 16 & 13 & 13 & 10 & 11 & 42 \\
\hline Belgium & 23 & 33 & 8 & 10 & 9 & 8 & 14 & 16 \\
\hline Denmark & 21 & 15 & 13 & 13 & 13 & 11 & 7 & 19 \\
\hline Finland & 16 & 12 & 10 & 6 & 14 & 19 & 3 & 30 \\
\hline France & 31 & 26 & 9 & 15 & 9 & 9 & 5 & 12 \\
\hline Germany & 13 & 33 & 10 & 18 & 10 & 15 & 10 & 20 \\
\hline Greece & 44 & 17 & 15 & 6 & 13 & 5 & 9 & 12 \\
\hline Ireland & 25 & 18 & 16 & 12 & 9 & 11 & 6 & 16 \\
\hline Italy & 46 & 24 & 13 & 8 & 6 & 6 & 6 & 8 \\
\hline Luxembourg & 26 & 18 & 22 & 11 & 9 & 12 & 13 & 12 \\
\hline Netherlands & 25 & 21 & 11 & 9 & 12 & 13 & 11 & 12 \\
\hline Portugal & 23 & 26 & 6 & 8 & 10 & 7 & 12 & 11 \\
\hline Spain & 37 & 31 & 16 & 10 & 26 & 13 & 21 & 3 \\
\hline Sweden & 17 & 25 & 10 & 6 & 10 & 16 & 6 & 21 \\
\hline UK & 27 & 15 & 13 & 8 & 10 & 11 & 11 & 3 \\
\hline EU average* & 28 & 25 & 12 & 12 & 11 & 11 & 10 & 12 \\
\hline
\end{tabular}

\footnotetext{
${ }^{*}$ Weighted according to population size.
} 
Table 6 Percentage of EU subjects selecting different perceived barriers to increasing levels of physical activity classified by demographics (age, sex and education level)

\begin{tabular}{|c|c|c|c|c|c|c|c|c|}
\hline \multirow[b]{2}{*}{ Perceived barriers } & \multicolumn{3}{|c|}{ Age (years) } & \multicolumn{2}{|c|}{ Sex } & \multicolumn{3}{|c|}{ Education level } \\
\hline & $15-34$ & $35-54$ & $55+$ & Male & Female & Primary & Secondary & Tertiary \\
\hline Work/study & 38 & 32 & 11 & 32 & 25 & 16 & 30 & 43 \\
\hline Not the sporty type & 22 & 27 & 27 & 22 & 28 & 32 & 23 & 21 \\
\hline Looking after children/elderly & 14 & 14 & 7 & 5 & 18 & 11 & 13 & 10 \\
\hline No need & 9 & 12 & 14 & 14 & 9 & 14 & 11 & 9 \\
\hline Poor health & 7 & 10 & 5 & 11 & 11 & 17 & 9 & 7 \\
\hline No energy & 9 & 11 & 14 & 9 & 13 & 14 & 10 & 10 \\
\hline Expense & 14 & 9 & 5 & 8 & 11 & 6 & 12 & 11 \\
\hline Too old & 2 & 4 & 28 & 10 & 10 & 19 & 7 & 4 \\
\hline Lack of facilities & 11 & 9 & 7 & 9 & 9 & 9 & 9 & 9 \\
\hline Other & 13 & 11 & 12 & 15 & 10 & 12 & 12 & 12 \\
\hline
\end{tabular}

than between member states. Among those with a tertiary education, $23 \%$ of subjects in Germany and Sweden selected the barrier 'work/study commitments' compared to almost two-third of Italians with the same education level.

For those who mentioned the barrier 'not the sporty type', almost half of the respondents said they took part in no physical activity, compared to a quarter of those who did not mention this barrier. The percentage of respondents who mentioned 'not the sporty type' varied by current body image, with an increase from $30 \%$ of subjects with current body image figures $1-3$ (low weight) to $45 \%$ of subjects with current body image figures 5-7 (overweight).

Participation in various physical activities was also looked at in terms of another perceived barrier 'no need to do more'. Respondents who selected this barrier had higher rates of participation in gardening and walking and had lower levels of non-participation (24\%), compared with those who did not select 'no need to do more' (32\%). This $24 \%$ of EU subjects represents a resistant group of inactive people who feel they do not need to be more active and presents those developing programmes which encourage increased levels of activity in the population with a formidable challenge.

\section{Discussion}

This study was intended to find new approaches to counteract the sedentary lifestyle of the European population. The results give much new information, especially for special risk groups. They demonstrate that most European individuals are quite wellinformed about lifestyle factors influencing health in a positive or negative way. No information could be obtained, however, to what degree the subjects responded to the questions in a socially desired way.

Classifying the subjects of the EU member states into demographic subgroups reveals that the positive value of physical activity for health is recognized more strongly with an increasing educational level. Detailed

Table 7 Percentage of subjects in each member state who selected the barrier 'not the sporty type' or 'work/study commitments' classified by education level

\begin{tabular}{|c|c|c|c|c|c|c|}
\hline \multirow[b]{2}{*}{ Country } & \multicolumn{3}{|c|}{ Not the sporty type } & \multicolumn{3}{|c|}{ Work/study commitments } \\
\hline & Primary & Secondry & Tertiary & Primary & Secondary & Tertiary \\
\hline Austria & 27 & 23 & 15 & 20 & 32 & 48 \\
\hline Belgium & 38 & 34 & 25 & 7 & 21 & 34 \\
\hline Denmark & 16 & 14 & 7 & 16 & 32 & 37 \\
\hline Finland & 13 & 12 & 15 & 7 & 19 & 27 \\
\hline France & 37 & 25 & 21 & 16 & 28 & 47 \\
\hline Germany & 37 & 29 & 27 & 6 & 18 & 23 \\
\hline Greece & 17 & 16 & 17 & 32 & 48 & 52 \\
\hline Ireland & 17 & 18 & 20 & 9 & 25 & 44 \\
\hline Italy & 31 & 23 & 20 & 21 & 48 & 64 \\
\hline Luxembourg & 21 & 19 & 12 & 17 & 25 & 42 \\
\hline Netherlands & 13 & 23 & 19 & 9 & 24 & 38 \\
\hline Portugal & 29 & 20 & 19 & 17 & 30 & 45 \\
\hline Spain & 34 & 26 & 27 & 33 & 43 & 51 \\
\hline Sweden & 29 & 22 & 26 & 10 & 19 & 23 \\
\hline UK & 14 & 15 & 15 & 12 & 23 & 43 \\
\hline EU average* & 32 & 23 & 21 & 16 & 30 & 43 \\
\hline
\end{tabular}

*Weighted according to population size. 
knowledge about the benefit of physical activity in prevention and therapy of cardiovascular diseases are not common in the whole population, but more obvious in patients who are at risk or already suffer from one. This lack of specific information may cause not only a lack of motivation to increase the individual level of exercise, but also a lack in translating healthoriented knowledge into health-oriented behaviour. Thus, there is only a limited or absence of stimulation to alter the personal lifestyle on a long-term scale. Only subgroups with elevated risk show a higher affinity to draw personal consequences from their situation and to change their everyday habits. This can be demonstrated among obese and overweight females. These subjects are more likely to perceive a benefit for weight control from their physical exercise than the rest of the population. However, the ability of subjects to estimate their personal level of activity is limited to a certain degree. One reason is that the term 'physical activity/ exercise' used in this study was defined in a rather broad sense. The study participants were forced to associate with the term not only sport exercise, but also all their everyday activities at work and during leisure time. Even with this information participants tended to underestimate the extent and duration of activities not typically associated with the image of physical exercise. Analogous to the phenomena of over- and under-reporting in dietary records, a similar behaviour is likely to be found in records of physical activity. As a methodical consequence it seems to be better to supply close-ended questionnaires on levels of activity to participants, so they can better control their own answers. The quality of recording may also be improved by a detailed list of several activities and by some explanations how these activities have to be recorded in respect to their duration and intensity ${ }^{12,15,24}$

From the study results it is obvious that the majority of respondents associate physical activity and exercise with being more a strenuous task and duty than with fun, recreation and relaxation. Mostly, physical activity is equated to sports. Therefore, many respondents mention 'not a sporty type' or 'too old' as a barrier and use this statement as an excuse not to increase their levels of activity. This is true also for many overweight and obese subjects who reject the idea of doing any sports and increasing their level of physical activity. They perceive a link between a lean body image and the level of activity. These subjects, especially older age groups, are not well enough informed about recent studies demonstrating the positive effects of moderate physical activity on health ${ }^{25-31}$.

To stimulate more people to be physically active it is necessary to be aware of the determinants of physical behaviour. There are a number of models which explain physical activity behaviour, but in general these include three sets of determinants: (1) knowledge and attitudes, (2) social influences, and (3) barriers and self-efficacy $^{32}$. In a review Sabha and Achterberg ${ }^{33}$ discussed the problems of recognition, interpretation and motivation arising in the complex of nutrition, activity and health-related behaviour. They demonstrated that outcome expectations, health belief and health value associated with health-related behaviour are not sufficient to release the necessary health-related action of an individual. The perceived barriers within the individual's consciousness can only be overcome by an improved self-efficacy and distinctive selfconfidence.

To achieve a higher level of physical activity in the population, however, not only behavioural but also social aspects have to be considered. The social side of prevention has to take into account the opportunity available to people to implement altered activities into their lifestyle, the situation at work and education, the national conditions of health-promoting measures and the reputation of the desired behaviour within the society. Thus, the public health message to increase physical exercise in a population base seems to be very simple, as published in the USA: 'Every US adult should accumulate 30 minutes or more of moderateintensity physical activity on most, preferably all, days of the week ${ }^{34}$. However, to be successful with such recommendations new preventive programmes have to focus both on personal and environmental conditions of the individual and the population.

Few studies in the EU, all of them on a national level, have looked at knowledge and attitudes towards physical activity ${ }^{35}$. The Allied Dunbar National Fitness Survey conducted in 1992 in the UK is one example, and examined attitudes to physical activity as well as the motivating factors and barriers to participate in physical activity ${ }^{36}$. No European study has, however, looked at the stages of change towards physical activity. One approach in the US, aimed at encouraging people to be more active, uses the stages of change model (PACE) ${ }^{7}$. This model describes the changes that need to take place for a more physically active lifestyle. While there are many programmes to tackle obesity in different countries in the EU most do so in the absence of knowledge of the attitudes towards physical activity and body weight. They also do so in the absence of the perceived motivating factors and barriers to physical activity and the stages of change towards physical activity.

\section{Conclusions}

Weight loss is best achieved by combining dietary intervention with increased amounts of physical activity. The most effective strategy for weight loss in either moderately obese or morbidly obese individuals appears to be a hypocaloric, low-fat diet combined 
with a moderate-intensity, moderate-duration resistance or aerobic exercise training programme. Increasing amounts of physical activity or maintaining high levels of physical activity for purposes of weight control might be most important in preventing the increases in weight known to occur with ageing, from the early twenties through to the late sixties. This pan-EU survey of consumer attitudes to physical activity, body weight and health is the first study to examine the attitudes of EU consumers from all 15 member states, together with obtaining a measure of prevailing levels of activity, inactivity and self-reported body weight. Some strategy recommendations to increase levels of physical activity in the EU and to stem the continuing rise in obesity, by means of preventing further weight gain are proposed based on the data arising from this pan-EU consumer attitudinal survey. The preventive aspect of physical activity must be an area of priority for future research attempting to better understand the role of physical activity in weight regulation.

\section{References}

1 Kuczmarski RJ, Flegal KM, Campbell SM, Johnson CL. Increasing prevalence of overweight among US adults. JAMA 1994; 272: 205-11.

2 Seidell JC. Obesity in Europe: scaling an epidemic. Int. J. Obes. 1995; 19: S1-4.

3 Biesalski HK, Liebermeister $\mathrm{H}$, Remke $\mathrm{H}$, Lehnert $\mathrm{H}$. Langzeittherapie des Übergewichtes-Effiziente therapeutische Ansätze und Prognose. Akt. Ernähr. Med. 1992; 17: 1-6.

4 Zelasko CJ. Exercise for weight loss: what are the facts? J. Am. Diet. Assoc. 1995; 95: 1415-17.

5 Fairburn CG, Cooper F. New perspectives on dietary and behavioral treatments for obesity. Int. J. Obes. 1996; 20: S9-13.

6 Hauner D, Hauner H. Leichter durchs Leben. Ratgeber für Übergewichtige. Strategien zum langfristigen Abnebmen. Stuttgart: Georg Thieme Verlag, 1996.

7 Calfas KJ, Long BJ, Sallins JF, Wooten W, Pratt M, Patric K. A controlled trial of physical counselling to promote the adoption of physical activity. Prev. Med. 1996; 25: 225-43.

8 Cowburn G, Hillsdon M, Hankey CR. Obesity management by lifestyle strategies. Br. Med. Bull. 1997; 53: 389-408.

9 Prentice AM. Obesity - the inevitable penalty of civilisation? Br. Med. Bull. 1997; 53: 229-37.

10 Gill T. Key issues in the prevention of obesity. Br. Med. Bull. 1997; 53: 359-88.

11 Sallis JF, Hovell MF, Hofstetter CR, et al. A multivariate study of determinants of vigorous exercise in a community sample. Prev. Med. 1989; 18: 20-34.

12 Blair SN, Kohl HW, Gordon NF, Paffenbarger RS. How much physical activity is good for health? Ann. Rev. Public Health 1992; 13: 99-126.

13 Wilmore JH. Increasing physical activity: alterations in body mass and composition. Am. J. Clin. Nutr. 1996; 63 (Suppl.): S456-60.

14 Paffenbarger RS. Physical activity, physical fitness, and coronary heart disease. In: Leaf A, Weber PC, eds.
Atherosklerose Reviews, Vol. 21. New York: Raven Press, 1990; 35-41.

15 Helmert U, Herman B, Shea S. Moderate and vigorous leisure-time physical activity and cardiovascular disease risk factors in West Germany, 1984-1991. Int. J. Epidemiol. 1993; 24: 285-92.

16 Mensink GBM, Deketh M, Mul MDM, et al. Physical acitivity and its association with cardiovascular risk factors and mortality. Epidemiology 1996; 7: 391-7.

17 Mensink GBM. Movement and Circulation. Population Studies on Physical Activity and Cardiovascular Disease Risk. Wageningen: Ponsen \& Looijen BV, 1997.

18 Lamb KL, Roberts K, Brodie DA. Self-perceived health among sports participants and non-sports participants. Soc. Sci. Med. 1990; 31: 963-9.

19 Fentem PH. Benefits of exercise in health and disease. BMJ 1994; 308: 2-6.

20 Flatt JP. McCollum Award Lecture: Diet, lifestyle and weight maintenance. Am. J. Clin Nutr. 1995; 62: 820-36.

21 Quinney AH, Ganvin L, Wall TA, eds. Toward Active Living. Champaign, IL: Human Kinetics, 1994.

22 Johnson NA, Boyle CA, Heller RF. Leisure-time physical activity and other health behaviours: are they related? Aust. J. Public Health 1995; 19: 69-75.

23 Kearney JM, Kearney M, McElhone S, Gibney MJ. Methods used to conduct the pan-European Union survey on consumer attitudes to physical activity, body weight and health. Public Health Nutr. 1999; 2: 79-86.

24 Duncan JJ, Gordon NF, Scott CB. Women walking for health and fitness. How much is enough? JAMA 1991; 266: $3295-$ 9.

25 Vorrips LE, van Staveren WA, Hautvast JGAJ. Are physically active elderly women in a better nutritional condition than their sedentary peers? Eur. J. Clin. Nutr. 1991; 45: 545-52.

26 Vaughan L, Zurlo F, Ravussin E. Aging and energy expenditure. Am. J. Clin. Nutr. 1991; 53: 821-5.

27 Reaven PD, Barrett-Connor E, Edelstein S. Relation between leisure-time physical activity and blood pressure in older women. Circulation 1991; 83: 559-65.

28 Owens JF, Matthews KA, Wing RR, Kuller LH. Can physical activity mitigate the effects of aging in middle-aged women? Circulation 1992; 85: 1265-70.

29 Wagner EH, LaCroix Z. Effects of physical activity on health status in older adults. I: Observational studies. Annu. Rev. Public Health 1992; 13: 451-68.

30 Fielding RA. The role of progressive resistance training and nutrition in the preservation of lean body mass in the elderly. J. Am. Coll. Nutr. 1995; 14: 587-94.

31 Bijnen FCH, Feskens EJM, Caspersen CJ et al. Physical activity and cardiovascular risk factors among elderly men in Finland, Italy, and the Netherlands. Am. J. Epidemiol. 1996; 143: 553-61.

32 Van Mechelen W. Can running injuries be effectively prevented? Sports Med. 1995; 19: 161-5.

33 Sabha A, Achterberg C. Review of self-efficacy and focus of control for nutrition- and health-related behavior. J. Am. Diet. Assoc. 1997; 97: 1122-32.

34 Pate RR, Pratt M, Blair SN, et al. Physical activity and public health. A recommendation from the Centers for Disease Control and Prevention and the American College of Sports Medicine. JAMA 1995; 273: 402-7.

35 Cavill N. National campaigns to promote physical activity: can they make a difference? Int. J. Obes. 1998; 22: S48-S51.

36 Fentem PH, Mockett SJ. Physical activity and body composition: what do the national surveys reveal? Int. $J$. Obes. 1998; 22: S8-S14. 


\section{Public Health Nutrition}

\section{Special Issues and Supplements}

Public Health Nutrition will publish special issues and supplements that concentrate on a particular topic. These fulfil the dual functions of contributing to the existing knowledge and providing an overview of the subject area.

The 1999 volume will feature the following supplementary issues:

- Diet and physical activity interaction for health

- Consumer attitudes to physical activity, body-weight and health in the European Union

All supplements and special issues will be supplied to subscribers as part of their annual volume. Apply to either the Editor-in-Chief or Editor for North America for further details or to suggest topics of interest.

Dr Barrie Margetts (Editor-in-Chief)

Institute of Human Nutrition

Southampton General Hospital

Southampton

UK

Tel: $+44(0) 1703796530$

Fax: $+44(0) 1703796529$

Email: bmm@soton.ac.uk

Dr Lenore Kohlmeier (Editor for North America)

Departments of Nutrition \& Epidemiology

Schools of Public Health and Medicine

Office 2105E, McGavran-Greenburg Building

University of North Carolina at Chapel Hill

NC 27599-7400

USA

Tel: +1 (919) 9667450

Fax: +1 (919) 9662089

Email: LenoreK@,unc.edu 


\section{Nuthition Desktop access to $c \vec{a} b w e b$ worldwide nutritional science information}

\section{Access these journals on the Internet in 1999:}

- British Journal of Nutrition

- $\quad$ Nutrition Research Reviews

- Proceedings of the Nutrition Society

- Public Health Nutrition

- Nutrition Abstracts and Reviews Series A: Human and Experimental

- Nutrition Abstracts and Reviews Series B: Livestock Feeds and Feeding

Access to the electronic version of each journal is FREE to members of institutions/organizations with a current print subscription to that journal. All you have to do is register.

For more information about this unrivalled resource in nutritional science information and for details of how to register, visit Nutrition CABWeb now at:

\section{http://nutrition.cabweb.org}

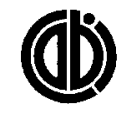

$\mathrm{CAB}$

$$
\text { Publishing }
$$

CAB International

Wallingford

Oxon, OX10 8DE, UK

Tel: $+44(0) 1491832111$

Fax: +44 (0) 1491829198

Email: publishing@ cabi.org
(1) CABI Publishing

$\mathrm{CAB}$ International

10 East 40th Street, Suite 3203

New York, NY 10016, USA

Tel: +1212 4817018

Fax: +12126867993

Email: cabi-nao@cabi.org 